\title{
The rapid growth of a pleomorphic adenoma of the parotid gland in the third trimester of pregnancy
}

\author{
Frederike Palluch ${ }^{1}$, Martin Lehmann ${ }^{1}$, Joachim Volz ${ }^{2}$, Tahwinder Upile ${ }^{3}$ and Holger Sudhoff ${ }^{*}$
}

\begin{abstract}
Introduction: We report a case highlighting the multidisciplinary management of a giant pleomorphic adenoma of the parotid gland that showed rapid growth in the third trimester of pregnancy.

Case presentation: A 43-year-old Caucasian woman presented in her 32nd week of gestation with a tumor of the parotid gland. Ultrasonography of her neck showed a parotid lesion of $40 \times 30 \times 27.5 \mathrm{~mm}$. A follow-up magnetic resonance imaging scan of the neck four weeks later revealed that the tumor had grown to $70 \times 60 \times 60 \mathrm{~mm}$, reaching the parapharyngeal space with marked obstruction of the oropharynx of about $50 \%$. After discussing the case with our multidisciplinary tumor board and the gynecologists it was decided to deliver the baby by caesarean section in the 38th week of gestation, and then to perform a surgical resection of the tumor.
\end{abstract}

Conclusion: Indications for early surgical intervention of similar cases should be discussed on an individual patient basis in a multidisciplinary setting.

\section{Introduction}

With an incidence of $65 \%$, pleomorphic adenoma is the most common tumor of the salivary glands [1], and $80 \%$ of the pleomorphic adenomas are located in the parotid gland. These tumors are characterized by slow growth over a period of years, and tend to remain asymptomatic. In $4 \%$ of cases, they turn into malignant tumors. In the following case report, we describe a pleomorphic adenoma of the parotid gland that showed rapid growth within the third trimester of pregnancy.

\section{Case presentation}

A 43-year-old Caucasian woman presented in her 32nd week of gestation with a tumor of the parotid gland. She had noticed the swelling increasing over the past six months. She was otherwise asymptomatic, without any pain, mouth-opening difficulties or facial nerve dysfunction. Ultrasonography of her neck showed a parotid lesion $40 \times 30 \times 27.5 \mathrm{~mm}$ in size, with an heterogeneous appearance. Considering her advanced state of pregnancy, we advised conservative management in the form of watchful waiting and regular review until the birth.

\footnotetext{
* Correspondence: holger.sudhoff@rub.de

'Department of Otorhinolaryngology, Head and Neck Surgery Klinikum Bielefeld, Bielefeld, Germany

Full list of author information is available at the end of the article
}

At our patient's next review, only five weeks later, we noticed rapid growth of the lesion with expansion into the parapharyngeal space. There was still no facial nerve involvement, although our patient's mouth opening was slightly limited. Magnetic resonance imaging (MRI) of the neck showed that the tumor had increased to $70 \times 60 \times 60 \mathrm{~mm}$, reaching the parapharyngeal space with marked obstruction of the oropharynx of about 50\% (Figures 1, 2). Further diagnostic tests such as fine-needle aspiration cytology (FNAC) were discussed. We were concerned about the risk of malignancy and increasing local complications due to the rapid growth. Considering the risk of spreading tumor cells and the unreliability of FNAC in identifying the malignant nature of parotid carcinoma [2], we decided to perform surgical resection to prevent further complications and to obtain a secure diagnosis.

After discussing this case with the gynecologists at our interdisciplinary tumor board meeting, it was decided to deliver the baby by caesarean section in the 38th week of gestation with epidural anesthesia using mepivacain and sufentanil. The surgical resection of the tumor was performed four days later. It was possible to completely remove the tumor via a standard cervicofacial incision without the need to resect the mandible. Although the tumor had stretched the facial nerve to double its usual 


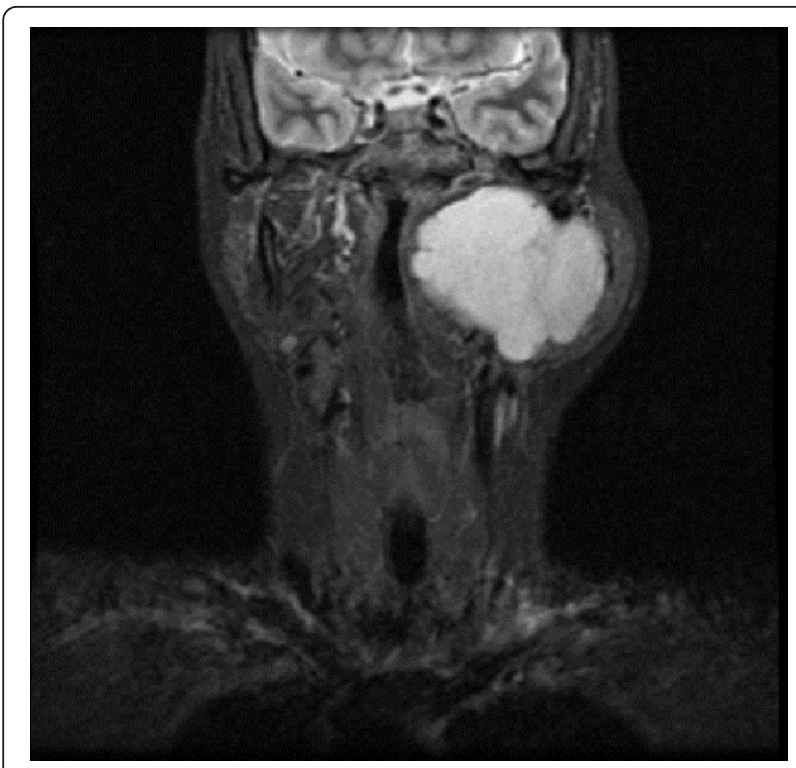

Figure 1 A coronal T2-weighted MRI of the head and neck region (36th week of pregnancy). The left parotid mass is seen distorting the pharynx. The outline of the heterogeneous lesion is clearly demarcated, and tissue planes preserved.

length, there was no postoperative nerve dysfunction (House Brackmann grade I).

On histological analysis, the lesion was identified as a pleomorphic adenoma without evidence of malignancy (Figure 3). Immunohistochemistry did not show any positive expression of oestrogen or progesterone

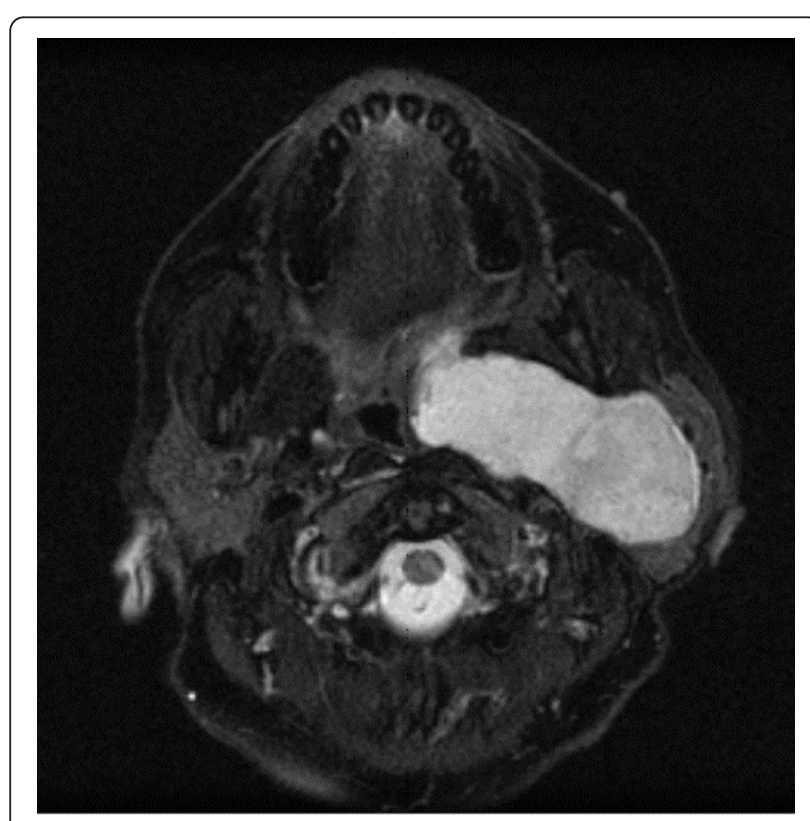

Figure 2 An axial T2-weighted MRI of the head and neck region (36th week of pregnancy). The outline of the

heterogeneous left parotid lesion is again clearly demarcated and tissue planes preserved. The oropharyngeal lumen is distorted.

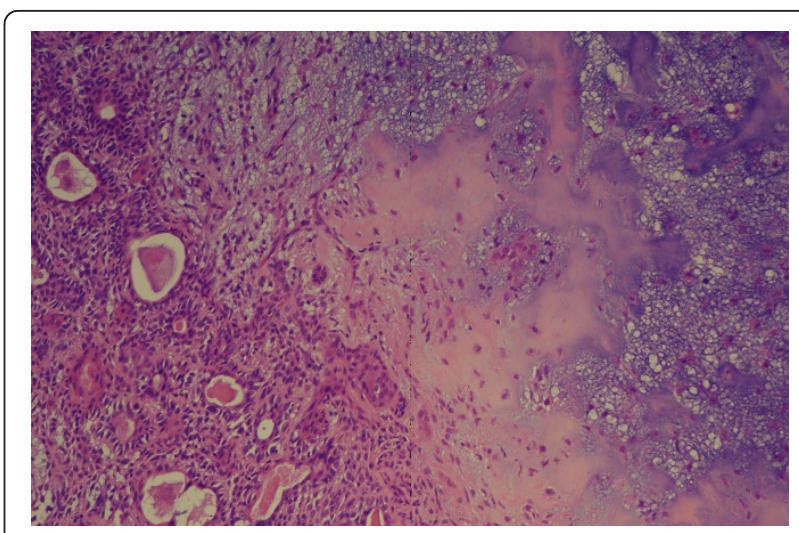

Figure 3 Pleimorphic adenoma without evidence of malignancy (hematoxylin and eosin, original magnification $\times 100$ ).

receptors. Our patient remained well with no evidence of recurrence after a follow-up of one year.

\section{Discussion}

The incidence of head and neck cancers during pregnancy is rising [3]. Pleomorphic adenomas are characterized by slow growth over a term of several years. Rapid increase or the appearance of facial nerve dysfunction may indicate malignant transformation, which has been reported in $4 \%$ of cases. Rapid growth during the third trimester of pregnancy may indicate a possible hormonal influence on pleomorphic adenomas. A scientifically based relationship is not proven [4-8]. There may be a prognostic association between the expression of progesterone receptors and recurrent pleomorphic adenoma of the parotid gland [9]. Although in this case described here, we could not establish such a relationship, it is possible that unknown factors (e.g. insulin-like growth factor, vascular endothelial growth factor human placental lactogen).are released by the fetoplacental unit, and that these stimulate growth in other end organs such as the parotid

\section{Conclusion}

We recommend frequent monitoring of tumors of the salivary glands diagnosed during pregnancy. Indications for early surgical intervention should be discussed on a individual patient basis in a multidisciplinary setting.

\section{Consent}

Written informed consent was obtained from the patient for publication of the manuscript and accompanying images. A copy of the written consent is available for review by the Editor-in-Chief of this journal.

\section{Author details}

'Department of Otorhinolaryngology, Head and Neck Surgery Klinikum Bielefeld, Bielefeld, Germany. '2Department of Gynecology and Obstetrics, Klinikum Bielefeld, Bielefeld, Germany. ${ }^{3}$ Visiting Fellow from Department of 


\section{Authors' contributions}

FP was the major contributor in writing the manuscript. ML helped to assemble the data and assisted with the manuscript writing. JV provided expert advice, performed the Caesarean section, and revised his part of the manuscript. TU helped to revise the manuscript, HS performed the gland surgery and performed the final reading of the manuscript. All authors have read and approved the final manuscript.

\section{Competing interests}

The authors declare that they have no competing interests.

Received: 4 January 2010 Accepted: 9 April 2011 Published: 9 April 2011

\section{References}

1. Eveson JW, Cawson RA: Salivary gland tumours. A review of 2410 cases with particular reference to histological types, site, age and sex distribution. J Pathol 1985, 146:51-58

2. Alphs HH, Eisele DW, Westra WH: The role of fine needle aspiration in the evaluation of parotid masses. Curr Opin Otolaryngol Head Neck Surg 2006, 14(2):62-6.

3. Atabo A, Bradley PJ: Management principles of head and neck cancers during pregnancy: a review and case series. Oral Oncol 2008, 44(3):236-41

4. Seifert G: Oralpathologie I. Pathologie der Speicheldrüsen. Springer Verlag Berlin 1996, Seite 365.

5. Laine $\mathrm{M}$, Ojanotko-Harri A: Progesterone metabolism by major salivary glands of rat. Parotid gland. J Steroid Biochem Mol Biol 1990, 37(4):605-11.

6. D'Alessandro S, Curbelo HM, Tumilasci OR, Tessler JA: Changes in human parotid salivary protein an sialic acid levels during pregnancy. Arch Oral Biol 1989, 34(10):829-31.

7. Nasser SM, Faquin WC, Dayal Y: Expression of androgen, estrogen, and progesterone receptors in salivary gland tumors. Frequent expression of androgen receptor in a subset of malignant salivary gland tumors. Am J Clin Pathol 2003, 119(6):801-6.

8. Larbcharoensub N, Cert PK, Tungkeeratichai J, Prakunhungsit S, Narkwong L, Leopairut J: Expression of hormonal receptor in patients with metastasizing pleomorphic adenoma of the major salivary gland; a clinicopathological report of three cases. J Med Assoc Thai 2009, 92(9):1250-5.

9. Glas AS, Hollema H, Nap RE, Plukker JT: Expression of estrogen receptor, progesterone receptor, and insulin-like growth factor receptor-1 and of MIB-1 in patients with recurrent pleomorphic adenoma of the parotid gland. Cancer 2002, 94(8):2211-6.

doi:10.1186/1752-1947-5-141

Cite this article as: Palluch et al:: The rapid growth of a pleomorphic adenoma of the parotid gland in the third trimester of pregnancy. Journal of Medical Case Reports 2011 5:141.

\section{Submit your next manuscript to BioMed Central and take full advantage of:}

- Convenient online submission

- Thorough peer review

- No space constraints or color figure charges

- Immediate publication on acceptance

- Inclusion in PubMed, CAS, Scopus and Google Scholar

- Research which is freely available for redistribution 